\title{
NARRATIVAS EN LA ENSEÑANZA SUPERIOR: ENTRE SENTIDOS Y SIGNIFICADOS DE LA FORMACIÓN EN CIENCIAS
}

\author{
Franciele Siqueira Radetzke \\ francielesradetzke@gmail.com. \\ https://orcid.org/0000-0002-3222-7977 \\ Roque Ismael da Costa Güllich \\ bioroque.girua@gmail.com \\ https://orcid.org/0000-0002-8597-4909
}

Universidade Federal da Fronteira Sul (UFFS), Brasil

Recibido: 2020-06-01; Aceptado: 2020-11-18

El artículo presenta los resultados de una investigación que estudia las perspectivas del proceso de educación continua en la Educación Superior (ES). Se centra especialmente en las titulaciones en el área de las Ciencias de la Naturaleza y sus Tecnologías (CNT) y en la formación de los profesores que participan en el programa de educación continua Ciclos Formativos en la Enseñanza de las Ciencias y las Matemáticas. Desde el punto de vista metodológico, el corpus de análisis estaba formado por las narraciones producidas por los profesores de la formación en relación con sus concepciones de la formación desarrollada. Para la discusión de los resultados se construyeron mónadas y las observaciones resultantes implican considerar algunas interacciones que emanan del conjunto de tales colocaciones, siendo ellas: la reflexión, las prácticas pedagógicas, las experiencias y la formación del formador. Estas interacciones se discuten en dos flancos principales: Reflexión y prácticas pedagógicas - enlaces necesarios y Experiencias de enseñanza - contribuyentes a la constitución de la formación.

Palabras-clave: Enseñanza superior; Mónadas; Formación de la enseñanza; Enseñanza de la ciencia.

\section{AS NARRATIVAS E O ENSINO SUPERIOR: ENTRE SENTIDOS E SIGNIFICADOS DA FORMAÇÃO EM CIÊNCIAS}

\section{Resumo}

$\mathrm{O}$ artigo apresenta resultados de uma pesquisa que investiga as perspectivas do processo de formação continuada no Ensino Superior (ES). Centra-se especialmente no tocante às licenciaturas da área de Ciências da Natureza e suas Tecnologias (CNT) e nos Professores formadores participantes do programa de formação continuada Ciclos Formativos em Ensino de Ciências e Matemática. Do ponto de vista metodológico, o corpus de análise foi constituído de narrativas produzidas pelos Professores formadores na relação com suas concepções acerca da formação desenvolvida. Para as discussões dos resultados foram construídas mônadas e as observações decorrentes implicam considerar algumas interações que emanam do conjunto de tais colocações, sendo elas: reflexão, práticas pedagógicas, experiências e constituiçãoformação do formador. Tais interações são discutidas em dois flancos principais: Reflexão e práticas pedagógicas - enlaces necessários e Experiências Docentes - contribuintes da constituição formação.

Palavras-chave: Docência Superior; Mônadas; Formação Docente; Ensino de Ciências. 


\section{NARRATIVES AND HIGHER EDUCATION: BETWEEN SENSES AND MEANINGS OF SCIENCE TRAINING}

Abstract

The article presents the results of a research that investigates the perspectives of the continuing education process in Higher Education (ES). It focuses especially on degrees in the area of Nature Sciences and its Technologies (CNT) and on the training teachers participating in the continuing education program Formative Cycles in the Teaching of Science and Mathematics. From a methodological point of view the corpus of analysis was made up of narratives produced by the training teachers in relation to their conceptions of the training developed. For the discussion of the results, monads were constructed and the resulting observations imply considering some interactions that emanate from the set of such placements, being them: reflection, pedagogical practices, experiences and the formation of the trainer. These interactions are discussed on two main flanks: Reflection and pedagogical practices - necessary links and Teaching Experiences - contributors to the formation constitution.

Keywords: Superior teaching. Monads. Teaching Formation. Teaching of Science.

\section{A docência no Ensino Superior: propósitos da investigação}

Tratar sobre o processo de formação docente é a intenção central do artigo recorrendose ao Ensino Superior (ES), especialmente no tocante às licenciaturas da área de Ciências da Natureza e suas Tecnologias (CNT) e à formação continuada como elementos-chaves de tal discussão. O encontro com o tema é um demarcar de desejos e esforços em compreender a profissão docente não como algo pronto e acabado, mas em convite ao diálogo com vistas a sua contínua (re)construção. O que nos propomos neste estudo não tem sido o início e nem o fim, mas os meandros da formação de Professores ${ }^{1}$, carregada de sentimentos, significados, anseios, perspectivas e desafios. Compreendemos a formação continuada como movimento necessário à compreensão e produção de identidades docentes, uma vez que: “a identidade não é um dado adquirido, não é uma propriedade, não é um produto. A identidade é um lugar de lutas e de conflitos, é um espaço de construção de maneiras de ser e estar na profissão" (NÓVOA, 2007, p. 16).

Não obstante, temos entendido a formação inicial como a base da construção de saberes que habilitarão futuros Professores à profissão (IMBERNÓN, 2001). Com efeito, os sentidos atribuídos e produzidos nesse contexto, de forma consciente ou não, perpetuam-se nos fazeres

\footnotetext{
${ }^{1}$ No texto, a palavra Professor é usada com inicial maiúscula com o intuito de demarcar o peso da expressão PROFESSOR, bem como o sentido da letra "P", atribuído por Nóvoa (2009), a partir de cinco outros "Ps", para formação e ação do Professor: P de Práticas; P de Profissão; P de Pessoa; P de Partilha e P de Público.
} 
profissionais docentes (CUNHA, 2005; GAUTHIER, 2006) e daí a necessidade de se olhar para a docência no ES, a fim de melhor compreender/perceber também quais as oportunidades/possibilidades e os desafios vivenciados pelo Professor Formador ${ }^{2}$ de Professores, da área de Ciências da Natureza e suas Tecnologias, ao formar novos Professores.

Em termos históricos, temos percebido no Brasil diferentes direcionamentos acerca dos processos de aprendizagem, reportando-se a desde quando o ensino universitário iniciou, em 1808, no período colonial, em que até então os brasileiros eram enviados à Europa para estudar e obter a formação de bacharéis e de doutores (PIMENTA, ANASTASIOU, 2014). Em termos de licenciatura, tais cursos foram instituídos no Brasil apenas em 1934: "com a finalidade explícita de oferecer aos bacharéis das várias áreas os conhecimentos pedagógicos necessários às atividades de ensinar" (PIMENTA, ANASTASIOU, 2014, p. 41).

Desde então, temos observado diferentes direcionamentos pedagógicos ao processo de ensinar e aprender, influenciados em sua maioria pelo contexto social que atribui possibilidades de mudanças, seja o contexto institucional vivido, momentos político-econômicos do país, formas de controle do conhecimento profissional, entre outros fatores que estimulam certos comportamentos didático-docentes e inibem outros (CUNHA, 1998). À vista disso, a forma pela qual se efetiva a relação entre Professor, aluno e conhecimento tem se modificado ao longo do tempo, ou seja, ao Professor não se incumbe mais a ideia de um profissional encharcado de conhecimentos a serem repassados aos alunos, mas uma relação de parceria colaborativa na direção da construção dos conhecimentos.

Desde o final da década de 90 podemos afirmar que o ensino universitário, especialmente no que se refere ao que forma novos Professores, passa a ser visto como um fenômeno complexo, visto em sua totalidade e valorizando a pesquisa em colaboração com investigadores e Professores de escolas, num movimento de reflexão crítica e coletiva das práticas pedagógicas (PIMENTA, ANASTASIOU, 2014). Dessa forma, de verdades prontas e indiscutíveis a universidade passa a constituir-se como finalidade ao exercício da crítica, ou seja, se ocupa da: "produção do conhecimento por meio da problematização dos conhecimentos historicamente produzidos, de seus resultados na construção da sociedade humana e das novas demandas e desafios que ela apresenta" (PIMENTA, ANASTASIOU, 2014, p.162).

\footnotetext{
${ }^{2}$ Aqui tomados os Professores do Ensino Superior como Professores Formadores de Professores da área de CNT e nos dedicamos especialmente a analisar o efeito da formação ligado às licenciaturas, dada sua importância na formação de novos professores.
} 
Em decorrência de tais encaminhamentos, questiona-se a formação docente no ES, uma vez que o Professor é colocado como elemento fundamental que pode favorecer a mudança, haja vista sua condição de dar direção e mediar a prática pedagógica que desenvolve (NÓVOA, 1992; CUNHA, 1998; IMBERNÓN, 2001). E ainda, há de se considerar que na formação inicial iniciam-se as primeiras compreensões que orientarão os futuros Professores no desenvolvimento de seus fazeres docentes (IMBERNÓN, 2001). Dessa forma, as atribuições ao Professor formador carregam uma dimensão oportuna de ser discutida, uma vez que pelo modo que ensina ele pode qualificar/contribuir ou não no processo de ensinar e aprender na educação básica, e daí a necessidade de se discutir suas compreensões e perspectivas junto aos processos de formação continuada.

Entretanto, observamos que em níveis de formação para o ES pouco se tem dado atenção ao desenvolvimento profissional, sendo que a condição necessária para atuação se dará preferencialmente em programas de pós-graduação stricto sensu (mestrado e doutorado) (BRASIL, 1996). Nesse sentido, a formação docente para o ES fica a cargo de iniciativas individuais ou institucionais. Em termos de docência no ES, a carreira acadêmica, geralmente, é valorizada mais pelas publicações e desempenho científico do que pela atuação em sala de aula, ficando as competências pedagógicas em segundo plano (CUNHA, 1998, 2005; ISAIA, BOLZAN, 2006; PIMENTA, ANASTASIOU, 2014). Tal situação supõe que o Professor dedique maior tempo e atenção às atividades de pesquisa do que às atividades inerentes ao processo de ensinar e aprender na sala de aula (JUNGES; BEHRENS, 2015), o que converge para sua atuação profissional.

Em vista de tais colocações, direcionamos atenção para a importância dos processos de formação continuada, também no ES, como campo profícuo ao desenvolvimento docente, uma vez que: "a formação continuada de Professores passa pela condição de que estes vão assumindo uma identidade docente, o que supõe a assunção do fato de serem sujeitos da formação, e não objetos dela" (IMBERNÓN, 2010, p.11). Tais perspectivas reforçam-se ao mesmo tempo em que vamos percebendo as possibilidades desse processo nas narrativas dos Professores em formação, participantes da pesquisa neste trabalho ${ }^{3}$.

\footnotetext{
${ }^{3}$ Neste trabalho, o campo empírico de investigação é constituído de narrativas dos Professores formadores, as quais foram gravadas em áudio e posteriormente transcritas. Como meio de identificação, os professores serão chamados de PES, referindo-se a professor do ensino superior, acrescentado de B (PESB), quando for da área básica, e de E
} 
No presente estudo, buscamos demarcar os pressupostos do processo de formação continuada vivenciado pelos Professores Formadores de Professores da Universidade Federal da Fronteira Sul (UFFS), Campus Cerro Largo, nos Ciclos Formativos em Ensino de Ciências e Matemática ${ }^{4}$, com vistas à constituição docente dos Formadores de Professores. Neste sentido, concordamos com Reis e Ostetto (2018, p. 4 [grifos dos autores]), ao afirmarem que: "o formar inexiste no a priori e é, antes, formar-se, processo permanente, abarcando transformações e aprendizagens realizadas pelo sujeito sobre si mesmo, nas interações sociais e no relacionamento com seu meio pessoal e profissional", é também uma perspectiva defendida por Mizukami (2002), de que a formação é um constante devir, num continuum estendido por toda a vida do docente.

A discussão acerca dos processos e necessidades da formação continuada na docência do ES tem sido temática recorrente em pesquisas da área (CUNHA, 2005; ISAIA, BOLZAN, 2006; IMBERNÓN, 2010; JUNGES, BEHRENS, 2015). No entanto, algumas passagens de narrativas dos Professores participantes desta pesquisa demonstram temáticas/desafios necessários de serem (re) pensados como possibilidades da formação em Ciências, entre elas: "fazer com que meus colegas pensem diferente, se sensibilizem” (PESBBio, 2019); “eu não gosto de escrever e por isso eu vejo os Ciclos como uma oportunidade de eu ver a minha prática e os sentimentos dos Professores da educação básica" (PESBFís, 2019); "é pouco tempo, porque é uma manhã" (PESBQui, 2019); "pensar em propostas e atividades para continuar a formação continuada” (PESEBio, 2019). Tais desafios e projeções nos convidam ao diálogo reflexivo, num repensar da produção de significados acerca da formação continuada, direcionando nossa atenção para os elementos que a constituem.

Para tanto, acreditamos que analisar as próprias concepções dos Formadores de Professores acerca do processo de formação continuada é tomada como elemento fundamental, uma vez que dá voz aos sujeitos participantes do campo de investigação, com o intuito de

(PESE), quando for da área do ensino, e ainda de Bio, Fís ou Qui, correspondendo às respectivas áreas de atuação (Biologia, Fisica ou Química).

${ }^{4}$ Programa de extensão vinculado pelo Grupo de Pesquisa em Ensino de Ciências e Matemática (GEPECIEM), da UFFS, Campus Cerro Largo. Constitui-se como oportunidade para fundamentar e produzir a formação de Professores (em formação inicial e continuada) por meio de encontros sistemáticos, estes que vêm ocorrendo uma vez por mês desde o ano de 2010, oportunizando o diálogo entre a formação inicial dos licenciandos envolvidos e a formação continuada dos Professores formadores e Professores da educação básica (tríade de interação, ZANON, 2003). Interessa-nos, particularmente, investigar o subgrupo que envolve apenas a área de CNT, denominado Ciclos Formativos em Ensino de Ciências. 
dialogar com estes as contribuições, necessidades e elementos que perpassam tais processos, uma vez que, segundo PESBFís (2019): “nos ciclos temos um coletivo de Professores, vários pensamentos em que é possível a troca de ideias e também a reflexão, já que durante as colocações não é? A gente se coloca no lugar do outro e também reflete sobre a própria atuação, é possível perceber acertos, qualidades e também equívocos, não é?". Essa narrativa nos fortalece rumo ao objeto de estudo na defesa da formação continuada como viés constitutivo dos Professores em formação, pela e na reflexão acerca da própria atuação docente, bem como no diálogo entre pares sobre suas concepções.

Ao encontro do processo de formação oportunizado pelos Ciclos Formativos, investimos no uso de narrativas como meio de investigação, considerando seu viés também formativo, quando: "dá aos indivíduos a possibilidade de articular, por meio das narrativas que produzem sobre si, as 'experiências referências' pelas quais passaram, dotando a própria trajetória profissional de sentido" (PASSEGGI; SOUZA; VICENTINI, 2011, p. 378). Neste caso, as pesquisas narrativas assumem duplo sentido, sendo utilizadas tanto para dados/como resultados de pesquisa como alternativa de formação (CUNHA, 1997; REIS, 2008). Dessa forma, os Professores, ao resgatarem suas experiências, refletem sobre seus processos de formação, permitindo a análise e nessa direção possibilitando a reformulação de seus saberes docentes e ainda, quando utilizado o compartilhamento, pode haver um processo de formação mútua.

Ao buscar pelos elementos constituintes do processo de formação vivenciado, que aqui está contextualizado, reportamo-nos que a escolha, por discutir as narrativas, vai ao encontro da busca de escuta das diferentes vozes emergentes do campo empírico, que de maneira contundente expressam os sentimentos que perpassam tais acontecimentos, dando voz e vez àquele que vivencia os encontros, em que pelas:

brechas de suas memórias, podem oferecer-nos imagens de um tempo e de um lugar. Em outras palavras, nossos trabalhos compõem um método investigativo que não busca o olhar do outro externo à experiência, mas, sim, a voz e o olhar daquele que vive e pratica o cotidiano da escola (ROSA; RAMOS, 2015, p. 146).

As narrativas foram produzidas por meio de escuta de histórias orais de formação dialogadas com a pesquisadora principal da investigação sobre a participação junto aos Ciclos, vivenciadas pelos Professores participantes da pesquisa. Em sua essência, a narrativa é carregada de muitos significados, sentimentos e entendimentos acerca da formação docente. 
Depois de transcritas, as narrativas foram textualizadas como meio de direcionar os enunciados, sem modificar o contexto de sua produção. Com esse direcionamento, segundo Rosa e Ramos (2015), é possível trabalhar com um tipo de textualização que denominam de mônada, que nas palavras das autoras são:

fragmentos de histórias que, juntas, narram a conjuntura de um tempo e de um lugar. Metodologicamente, elas são excertos das transcrições das entrevistas que são recriadas mediante textualização, produção de um título e edição. Expressam-se como pequenas crônicas, historietas com início e final geralmente aberto, que deixa brechas para que o leitor ou o ouvinte possa também, criativamente, perceber as verdades que elas contêm (ROSA, RAMOS, 2015, p. 147).

Com essa perspectiva, propusemo-nos à construção de mônadas como meio de diálogo, uma vez que, a partir das narrativas concedidas, entendemos cada uma delas como sendo única, perfazendo cenas distintas com potencial formativo/constitutivo dos Professores em questão e dos outros do discurso por extensão na leitura destas histórias. Para Reis (2008, p. 7), o objetivo da análise de narrativas docentes não é sua generalização, "mas sim o estudo das particularidades e da complexidade de cada caso, ou seja, da realidade específica de cada sujeito, dos sentidos particulares que atribui a essa realidade e das explicações e dos argumentos que apresenta”.

Dessa forma, como já mencionado, todas as histórias orais narradas foram gravadas em áudio, transcritas e textualizadas, as quais constituíram-se em mônadas (ROSA; RAMOS, 2015). Na discussão, os Professores serão chamados de PES, referindo-se a Professor do ES, acrescentado de B (PESB), quando for da área básica, e de E (PESE), quando for da área do ensino, e ainda de Bio, Fís ou Qui, correspondendo à área de atuação: Biologia, Física e Química, respectivamente. Tal investigação delineia-se como pesquisa de abordagem qualitativa (LÜDKE; ANDRÉ, 1986), em que, como meio de constituição do campo empírico, foi desenvolvida uma investigação-formação-ação (ALARCÃO, 2010; GÜLLICH, 2013), com uso das narrativas como estratégia e metodologia de investigação para produção dos resultados, pois: "permite uma melhor compreensão do conhecimento dos Professores através da análise das suas próprias palavras" (REIS, 2008, p. 6). Na sequência, apresentamos o cenário em que as histórias aconteceram.

\section{O cenário em que as histórias aconteceram: os Ciclos Formativos em Ensino de Ciências}


E cá estamos dialogando o Ser Professor em momentos de FormAção.

Os quais nos fazem pensar, que nos deixam inquietos e pensantes.

Um silêncio que agora se encontra a tremer pelas provocações e discussões que ganham força ao passo que se discutem Ações, Anseios, Medos, Entendimentos e as

Possibilidades que não se cessam!

São minutos de turbulência que agitam pensamentos e a certa altura já convidam outras vozes a expressar sentimentos, quando todos juntos buscam pela mesma resposta: $O$ que nos torna Professor? ${ }^{5}$

A citação que escolhi para iniciar a discussão é trazida como sinônimo aos processos formativos desenvolvidos pelos Ciclos Formativos e não só por ele, mas também acerca do diálogo com os Professores entrevistados dos quais as discussões foram sendo produzidas e como 'pérolas' mereciam de serem tratadas/contempladas. Em tom que desse mais vida às discussões, buscamos junto às expressões dos próprios Professores contextualizar o cenário que suas narrações descrevem e buscam apresentar: dos Ciclos. No referido estudo foram pesquisados seis Professores atuantes no ES da UFFS, Campus Cerro Largo, participantes do processo de formação continuada. Dos Professores investigados, dois são da área de Ciências Biológicas, dois da Física e dois da Química, sendo três com formação de Pós-graduação na área básica de Biologia, Física e Química e os outros três com Pós-graduação em Educação, sendo escolhidos aos pares por área e formação, com vistas a compreender se decorrem implicações do processo de formação continuada em cada campo de atuação e vice-versa.

Ao realizar a escuta das histórias/narrativas orais sobre a formação, atuação de cada um dos Professores participantes da pesquisa, bem como sobre a sua participação nos Ciclos Formativos, percebemos que os cenários que foram sendo descritos eram completamente diferentes, pois cada Professor, com suas particularidades, seus desafios e seus entendimentos, deu seu próprio contorno a sua história, no que podemos afirmar que é o papel das narrativas constituir os sujeitos de suas histórias (CUNHA, 1997; REIS, 2008).

As narrativas (dados deste estudo), assumidas como viés formativo, produzem sentido maior quando postas em discussão e dialogadas no encontro de outras vozes, uma vez que, para Reis e Ostetto (2018, p.6): “as narrativas possibilitam o entrelaçamento das vidas do narrador e

${ }^{5}$ Citação retirada do Diário de Formação da autora. Nesse, as escritas são realizadas com base na perspectiva de Porlán e Martin (1997), que nomina o diário como Diário do Professor, uma forma mais autêntica de investigação-ação, pesquisa da própria prática. Importante destacar que o desenvolvo como Professora pesquisadora desde minha formação inicial, no que tem me acompanhado até aqui e guarda, por certo, a história de minha investigação-formação-ação. 
do ouvinte que, ao compartilhar dos relatos do narrador, pode tanto reinterpretá-los, quanto recriá-los consoante às suas próprias formas de pensar, sentir e agir”. Desse modo, é por meio das histórias de vida dos Professores pesquisados, as quais retratam o fazer pedagógico, que buscamos destacar os elementos constituintes do processo de formação vivenciado, acreditando que: "pelas histórias de vida podem passar a elaboração de novas propostas sobre a formação de Professores e sobre a profissão docente" (NÓVOA, 2007, p. 25).

O processo de formação desenvolvido pelos Ciclos Formativos busca articular formação inicial e continuada pautada na racionalidade crítica, que implica pensar uma formação através do modelo de Investigação-Formação-Ação (IFA) (CARR; KEMMIS, 1988; CONTRERAS, 1994,2002; ALARCÃO, 2010; GÜLLICH, 2013), em que:

a essência do modelo é muito simples. Por processos de observação e reflexão, a experiência é analisada e conceitualizada. Os conceitos que resultam desse processo de transformação servem, por sua vez, de guias para novas experiências, o que confere à aprendizagem também um caráter cíclico e desenvolvimentista (ALARCÃO, 2010, p.53).

Dessa forma, junto aos Ciclos Formativos o processo de IFA tem sido assumido como possibilidade constitutiva dos Professores participantes, uma vez que é instigada a reflexão acerca da prática docente de forma colaborativa e em diálogo com referentes teóricos. Nas palavras de Güllich (2013, p.268): “a aprendizagem que se dá no contexto da IA [Investigação Ação] é um processo que transforma a experiência pela via reflexiva, com isso adquire potencial formativo". Nos ciclos formativos, os encontros acontecem uma vez por mês, em que, a partir de atualizações temáticas conceituais e pedagógicas, diálogos formativos, escritas reflexivas e sistematização de experiências, são discutidas questões que permeiam o contexto educacional e os processos de formação de Professores.

Ainda, junto aos Ciclos Formativos pode ser observado um espaço de coletividade, onde se instiga o compartilhamento de experiências, em que a formação:

[...] tem ocorrido de modo coletivo e busca a autoria compartilhada que implica na participação de três tipos de sujeitos durante o processo: Professores formadores da UFFS, licenciandos da UFFS dos cursos de Ciências Biológicas, licenciatura em Física e licenciatura em Química e Professores da educação básica de ciências e matemática, todos considerados como Professores em formação (GÜLLICH, HERMEL, BULLING, 2015, p.168). 
O processo formativo, ao perfazer os três níveis de ensino (formação inicial, Professores da educação básica e Professores formadores), implica considerar a tríade de interação enfatizada por Zanon (2003), em que sujeitos com distintas funções no processo interagem para investigar/criar/propor práticas e currículos. Consideramos a importância de tais interações à medida que instigam o compartilhamento de experiências, consolidando-se em espaços de formação mútua: "nos quais cada Professor é chamado a desempenhar simultaneamente, o papel de formador e de formando" (NÓVOA, 1995, p. 26).

Também é oportuno salientar o processo de escrita reflexiva, proporcionado com o Diário de Formação produzido de acordo com a perspectiva de Porlán e Martin (2001). Os autores ressaltam que o diário do Professor: "é usado como um guia para a reflexão sobre a prática, favorecendo ao Professor a consciência sobre seu processo de evolução e sobre seus modelos de referência" (2001, p.22). Assim, as escritas/reflexões construídas acerca das vivências na docência buscam desenvolver, em quem dela usufrui como seres críticos e reflexivos, um repensar constante das ações empreendidas e assim se tornam experiências, ou seja, já estão transformadas (LAROSSA, 2002). As diferentes concepções, posições, elementos constituintes apresentados e que permeiam o transcurso e conteúdo das mônadas, que a seguir são discutidas, não são trazidas como início ou fim da discussão. São elementos que constituem tais espaços e determinados tempos de formação, apresentam-se como 'pérolas', que como partes de um todo apresentam uma história de formação, um enlace de perspectivas e de concepções que, ao serem compartilhadas, caminham na construção de um ornamento carregado de ideias e saberes postos/abertos em/a discussão.

Dessa forma, pelas narrativas dos Professores de ES em formação e pelos seus entrelaçamentos com o contexto dos Ciclos Formativos, buscamos os elementos constituintes do processo formativo vivenciado. Na sequência, é apresentado o conjunto de pequenas histórias: as mônadas, produzidas e pautadas conforme metodologia de Rosa e Ramos (2015). Neste sentido, inicialmente são somente apresentadas como um conjunto de textos sem categorização prévia, tampouco nenhum tipo de classificação, produzindo efeitos de compreensão dentro de um regime de verdades, dentro do seu contexto e do outro que as lê, ao estabelecer seu diálogo com a história. Assim, são organizadas mediante textualização, produção de um título e edição, expressando-se como pequenas crônicas (ROSA, RAMOS, 2015). Passamos, então, a apresentá-las na próxima seção. 


\section{Narrativas de formação em Ciências são 'pérolas a serem compartilhadas}

\section{Formação e Ensino: um movimento que se transforma pela Investigação}

Eu, na verdade, acho importantíssimo para a formação [referindo-se aos ciclos formativosformação continuada], então tem muitas coisas que eu estou adaptando. Então, é um processo para quem não é da área do ensino, mas pelo menos tem a intenção de melhorar a cada dia essa questão, mesmo sendo da específica valorizo muito o ensino, já que é um curso de formação de Professores. Então, os Ciclos está sendo muito importante para esta, essa minha formação. Isso faz com que eu consiga transpor para a sala de aula, não é? Então, essa experiência que os Ciclos está me passando me ajuda muito, sem dúvida, talvez eu nem perceba isso, mas é que eu não tenho esse hábito de escrever, eu tenho dificuldade nessa escrita, nessa autorreflexão. Não sei se vou conseguir isso ainda um dia, com quase 50 anos já vem com uma bagagem de quase 20 anos no ensino de graduação, mas aquele ensino tradicional. Mas eu vou quebrando isso a cada ano e os Ciclos pode dar um salto maior a isso. É a gente está sempre em metamorfose [transformação], como eu digo, não é? E os Ciclos tem um papel eu acho muito importantíssimo, ele sensibiliza e tem que sensibilizar quem está participando, e, é isso, que eu acho o principal papel dos Ciclos. Ele tá me sensibilizando mais do eu imaginava, não é? Eu sempre fui crítico nas minhas aulas, e isso me ajuda a evoluir em termos de Professor. E os Ciclos ajuda, eu, a pensar mais nessa criticidade do meu ser Professor, então isso eu acho que é bem importante. Eu acho, o principal desafio é ainda, talvez uma coisa tópica minha, é fazer com que meus colegas pensem diferente, se sensibilizem, principalmente da área especifica. Isso, talvez no futuro, eles se sensibilizem que é um curso de formação. Não estou dizendo para eles não trabalharem com as específicas que são muito importantes, mas também pensarem que estão num curso de formação, que estão formando Professores. É o trabalho para quando vocês chegar lá, futuros Professores e até nós mesmos, de como a gente vai fazer com que eles consigam assimilar, não digo nem assimilar, mas como eles vão trabalhar com esses conteúdos em sala de aula, já estar repetindo o que os Professores fazem aqui[no sentido de modificar a realidade]. Talvez um grande desafio no meu caso, para mim seja eu conseguir conciliar a disciplina especifica com esse olhar voltado para a formação de Professores e também 
trabalhar no ensino. E eu gosto das duas coisas, eu me sinto realizado trabalhando com a específica também (PESBio, 2019).

\section{O diálogo com a Educação Básica: realidades e necessidades}

Porque eu acho que a gente não pode perder o contato primeiro com aquilo que está sendo lá na básica, não é? Tanto eu não posso perder o meu olhar quando eu era estudante, das minhas dificuldades. Então eu não posso perder isso, nem em pensamento e nem em reflexão, nem naquilo que eu posso aproveitar daquilo que os outros estão falando. Então minha preocupação é essa: é tentar sempre trazer a realidade e já estar pensando, se colocando naquele ambiente e não de uma forma distorcida. Então os Ciclos ele traz isso, porque ele traz uma sala lotada de alunos que estão ali e eu posso ver as reações e vejo as apresentações tanto dos alunos quanto dos Professores e isso me mantém aproximada. Quando eles têm as suas falas a gente consegue se aproximar, das angústias que se tem nas escolas e isso é importante que a gente tem que manter, ajudar como formador e os Ciclos permite isso, não é?, Continuamente repensar as situações da sala de aula e da formação, de estar presente, sabendo conscientemente o nosso papel então tá unindo os Professores não é? É um tripé. E esse é o nosso propósito não dá para se afastar e os Ciclos permite isso. Claro que é pouco tempo, porque é uma manhã, se a gente pudesse falar mais, teria muito mais coisa, fica limitado sempre no tempo, não é? Mas já é um começo. A gente vai afunilando, especificando [em pesquisas de mestrado e doutorado] mas a gente sempre precisa voltar, a gente só estuda uma parte bruta e específica. Então o básico que ajuda explicar o que é complexo às vezes vai ficando pra trás em termos didáticos de transformação, de como ensinar pra um aluno que está vendo pela primeira vez? Então a gente tem que se adequa assim como as tecnologias, a gente precisa é uma necessidade [dos Ciclos]. É essa parte, mais da parte pedagógica que eu sinto que o Ciclos nos fornece. Por que como não tem no mestrado, não tem no doutorado a gente vai pensando de um jeito e aí se a gente não se deixa mudar, pelo conjunto e pelas necessidades que se encara e se não tiver o contato, é como se ficasse perdido nessa caminhada e ali [nos Ciclos] a gente não está sozinho, então os Ciclos ele permite esta junção de repensar e de não me tornar egoísta nesse sentido não é? Então eu tenho que pensar em mim na hora de falar, eu tenho que falar pensando na realidade, no contexto dos que estão se formando. Cada um que faz um estudo é 
um acréscimo. Permite um contato maior. Ah eu não estou participando! Não, eu preciso, porque eu preciso me renovar a cada dia, então é importante. É isso aí, um desafio preciso, uma necessidade (PESBQui, 2019).

\section{Formação colaborativa: reflexão sobre o papel do Professor}

É bem, eu acho que ver a prática pedagógica e também me colocar como Professor da Educação Básica porque a gente não pode fugir de que são Professores que estamos formando. E lá [referindo-se aos ciclos formativos- formação continuada] nós temos esse contato e entre os diálogos e colocações, não é? É possível observar também a nossa prática enquanto formadores, então eu vejo essa, essa possibilidade nos Ciclos. Tem mudado um pouco a forma de eu dar aula, agora faço trabalhos em grupos, deixo mais eles [alunos] se organizarem, eu trago artigos e eles se organizam em grupos para discutir. Aí eles interagem mais, e eu vou descobrindo o meu papel, que não é só passar o conteúdo de forma mecânica, mas ser mais flexível e fazer com que eles participem. E nos ciclos temos um coletivo de Professores, vários pensamentos em que é possível a troca de ideias e também a reflexão, já que durante as colocações né, a gente se coloca no lugar do outro e também reflete sobre a própria atuação, é possível perceber acertos, qualidades e também equívocos, não é? Eu sempre digo pro Professor $R$ que eu não gosto de escrever e por isso eu vejo os Ciclos como uma oportunidade de eu ver a minha prática e os sentimentos dos Professores da Educação Básica, eu acho que o meu principal desafio seja eu me colocar, eu me ver como um Professor da Educação Básica porque nós estamos formando Professores uma profissão que precisa ser capaz de transpor conhecimentos conceitos e que eu acredito ser interessante de forma colaborativa e daí a necessidade que vejo dessa relação orgânica entre a Universidade e as escolas. Eu me formei na área técnica mesmo, e o Professor se forma em um termo específico, responde a apenas uma pergunta, mesmo os da área do ensino no final o campo de estudo se direciona a uma temática apenas ficando alienado das demais. Então provocar esse processo diferenciado de dar aulas é algo novo pra mim e que precisa ser construído e os Ciclos provoca isso (PESBFis).

\section{Os diálogos coletivos como combustível para a prática docente}

Eu fico numa expectativa muito grande para os Ciclos cada mês. Porque, para mim, além da formação é o momento da gente se reencontrar no grupo. O fato de nós estarmos lá todos juntos 
sabe, de ver, olhar o grupo todo de quem faz de quem é ali isso tudo pra mim é muito importante esse coletivo. Acho que o mais importante, o significado mais importante dos Ciclos é a coletividade e o compartilhamento que a gente tem lá dentro, das questões teóricas, das experiências vividas, é uma riqueza assim muito grande, em alguns momentos mais, em alguns momentos menos, mas isso é um ciclo que vai passando, por isso Ciclos Formativos, porque não é sempre 100\%, a gente não está $100 \%$ às vezes fazendo. Então a gente tem momentos em que a gente tem que ficar mais em silêncio às vezes participa mais, tem vezes que é mais teórico, tem vezes que a gente tem que retornar e ir mais para a sala de aula, não é? Buscar as experiências da sala de aula, fazer com que os Professores falem da sala da sua aula, tem vezes que a gente precisa reforçar textos teóricos pra ir compreender coisas que ocorrem na sala de aula e na prática. Então, pra mim, é um momento em que eu me encontro com os colegas e reacende aquela chama da coletividade. Para a minha prática, os Ciclos é o combustível da prática dos Professores formadores independente, claro eu tenho vários alunos do curso de Química que não participam dos Ciclos, são alunos de fora, enfim trabalham, mais participam são os bolsistas. No dicionário dos ciclos formativos não tem a palavra desistir ou cancelar, ocorre Ciclos Formativos para o Ensino de Ciências com quatro ou cinco pessoas eles ocorrem, porque foi o que eu percebi na tese, não influi o número de pessoas e também não influi se um é transformador ou conservador, um é tradicional, um é crítico, é necessário que todos esses estejam no nosso grupo pra que esse grupo se movimente, porque a formação dos Ciclos ela é, eu percebo ela como um movimento constante que ora, como eu disse antes, ela é mais intensa, no sentido de evoluir nó vamos a passos largos às vezes e saímos de lá extremamente satisfeitos com o processo, ora a gente retrocede, não é? Ora a gente tem que refletir outras situações, não é? Então esse movimento de retroceder de evoluir ele é necessário para que o próprio Ciclos Formativos se mantenha, esse eu acho que é o próprio combustível dos Ciclos Formativos, não é? Essas diferenças que nós temos esse constante reprogramar, refazer, não é? Eu acho que isso é muito qualificador no grupo, eu aprendi muito nos Ciclos. (PESEQui, 2019).

\section{Novos olhares a partir do diálogo e da interação}

Eu acho importante a gente estar sempre refletindo sobre situações diferentes, porque a gente tem o nosso mundinho, as coisas acontecem de certo modo, e quando a gente vai começar a 
perceber outras possibilidades de trabalho, outras formas de trabalho porque cada um que vai lá, que faz a sua fala traz um olhar diferente sobre aquela mesma educação que a gente pensa que entende. Então essa é a formação sempre continuada, porque tu está sempre aprendendo, a gente nunca para de aprender e a importância de estar lá [referindo-se aos Ciclos] sempre querendo novos olhares, novas possibilidades, novos conhecimentos que são apresentados para todos nós, para todos os níveis de formação que estão lá. Outras possibilidades pro nosso crescimento, que a partir de novos olhares a gente vai percebendo outros caminhos, outras possibilidades, outros caminhos para seguir e não ficar só, até porque vai estagnar, vai chegar um momento que você vai fazer sempre a mesma coisa, que vai estagnar e tu não vai ter mais o que fazer, tu vai fazer sempre a mesma coisa como se dizia lá, tu vai ter as páginas amareladas usar sempre as mesmas, mas não vamos usar outros meios de crescimento. A importância está como eu te disse antes de pensar novos modelos de agir e de desenvolver o trabalho na sala de aula e isso também influencia nos estudantes que estão lá, afeta não só a mim afeta a todos eles também começam a pensar em outras formas e trazer para discussão na aula e isso vai fazendo com que eu mude minha aula, porque a cada semestre a gente vê o que deu certo e o que não deu, sempre repensando embora as disciplinas sejam sempre as mesmas tem uma sequência, mas a maneira a cada semestre é diferente do anterior, a gente está sempre buscando melhorar (PESEFis, 2019).

\section{Reflexão, formação e constituição docente}

Se eu não quisesse não precisava fazer porque o município aquela vez não exigia, eu comecei a vir porque eu queria participar, e eu acho que é importante a gente sempre estar aprendendo, estar num processo contínuo de constituição, que não é porque eu estou aqui que eu sei mais que os outros, não é? Mas a gente sempre aprende ouvindo o outro, então sempre tem uma coisa ali que vai agregar na tua formação e mesmo pra você repensar outras coisas que a gente está fazendo. Mas agora com essas formações continuadas que têm pelo NAP eu vejo outros Professores vindo, mas eu vejo que não é uma preocupação assim com a formação do formador. E também é uma exigência né e aqui acho que não tem, agora que está começando esse ano com o processo do NAP que está indo, mas você vê que não é todos que vão, você já participou, não é? Eu acho que é um momento importante porque a gente como formador, tu és formador, mas tu não estás formado, tu estás num processo, como eu te disse de constituição, a gente está 
todo dia aprendendo uma coisa ou outra. Então quando tu vai e participa dessas formações como teve esses dias o primeiro encontro é importante parar e olhar, ah uma reprovação em massa, fazem pensar será que não sou eu, será que não é comigo é, eu tenho que descer do meu pedestal e olhar pra onde eu estou, rever se é um grande número, não é eles pode ser eu! É aquela coisa das marcas, não é? Tem uma coisa ali que tu vais aproveitar provavelmente. A questão da avaliação, por exemplo, que a Professora $R$ trabalhou, então tu vais pensar diferente esse ponto da avaliação, assim como outros temas, a experimentação, o trabalho de experimentação. Mas assim dizer que eu parei e fiz essa reflexão isso lá e isso aqui, não eu não pensei sobre isso, mas provavelmente tem reflexos de lá na minha prática. Quando você começa a participar de um processo formativo, você vai ampliando teu olhar, começa a se questionar, aí tu vais ter mais subsídios para uma discussão. Então dentro do curso se os Professores participam da formação continuada, não é? Começam a enxergar, se sensibilizam com essa questão talvez aí mudando o jeito de ele trabalhar em sala de aula, o jeito da avaliação que ele vai aplicar. Mas parte dessa vontade de querer, porque é muito mais prático ficar em casa do que vir aqui e querer mudar sair da zona de conforto pensar algo diferente, pensar que não é porque eu sou doutor ou phd em tal área que eu não possa descer e ver o nível em que meus alunos estão e ver o que, de fato, eles estão precisando para aprender (PESEBio, 2019).

\section{$O$ adensamento das pérolas: brechas a serem consideradas}

Neste estudo, investimos no uso de narrativas como viés de investigação, ensino e também de formação, uma vez que oportuniza espaços de diálogo para as histórias de formação, de saberes e práticas (REIS, 2016). Ao discutir as ações pedagógicas e a necessidade da formação continuada, Nóvoa $(2007 ; 2009)$ enfatiza que a maneira pela qual o Professor se desenvolve didaticamente está relacionada à sua maneira de ser e com as suas relações pessoais. O que implica mobilizar dimensões pessoais nos espaços de formação e o diálogo da prática docente como meio de reflexão e também de formação.

Diante das narrativas produzidas pelos Professores e à luz de uma possibilidade de interpretação/compreensão das mônadas ${ }^{6}$, nos implicamos em: “aceitar que por detrás de uma -

6 Uma possibilidade de intepretação e compreensão será apresentada neste texto como forma de discussão das histórias pequenas: Mônadas, porém esta não é a única. Conforme Rosa e Ramos (2015), a interpretação é livre, pessoal, única de explicar determinado acontecimento! 
logia (uma razão) há sempre uma - filia (um sentimento), que o auto e o hetero são dificilmente separáveis" (NÓVOA, 2007, p.25 [grifos do autor]). Tal pensamento direciona-se ao observarmos que os dizeres dos Professores investigados são carregados de experiências e sentimentos entendidos como determinantes na ação pedagógica, justificando os meios pelos quais atuam. Diante de tais perspectivas, Maldaner (1997, p.1), ao trabalhar com a formação continuada de Professores, ressalta a necessidade de "dar voz aos que fazem a educação por seu trabalho, os Professores, e permitir assim, a sua qualificação e profissionalização”, o que requer a participação dos Professores na realização de estudos e pesquisas sobre a própria prática educacional (MALDANER, 1997).

Dessa forma, faz-se oportuna, em momentos de formação, a discussão de temas pedagógicos e experiências docentes, dando voz à prática pedagógica, assim como tem sido realizado pelos Ciclos. A circunstância de dar voz às memórias carregadas de significados, sentimentos e sonhos (ROSA, RAMOS, 2015), materializa-se na possibilidade do diálogo com outros e na possibilidade do alcance de outras projeções e desafios. Para Larrosa (1998, p. 38): "quando contamos nossas histórias e experiências para os outros, de forma escrita ou oral, elas deixam de ser somente nossas, pois passam a fazer parte da vida do outro". Assim, destaco a importância dos aspectos relacionados à história de formação, conjunturas atuais e possibilidade de um arranjo, em que, juntas, as "pérolas" são capazes desdobramentos mais resistentes e significativos, que no percurso das mônadas demarcam elementos emergentes, como os sentidos atribuídos.

Ao discutir os elementos que emergem das narrativas, não pretendo aqui encerrar um ciclo. Se esse fosse o objetivo, encerraríamos a escrita por aqui. Pretendemos traçar diálogos junto aos entendimentos dos Professores e trazer as oportunidades e os desafios da docência, quando em processos de formação continuada que envolvem a docência no ES. Assim, intencionamos iniciar ciclos e discussões, e quando voltarmos à discussão, talvez a realização de novos processos de formação venham à tona com diferentes ornamentos, sempre à deriva, em reconstrução.

É assim que, mesmo considerando as singularidades que cada narração representa, permitimo-nos analisar as características interativas que são compartilhadas, indiciando os elementos constituintes do processo de formação, como possibilidade de pensar novos ciclos e desafios. Com olhar para as "brechas" consideramos como elementos-chaves para a discussão: 


\section{a reflexão, práticas pedagógicas, experiências e a constituição-formação do professor}

formador. No entanto, "as narrativas não serão categorizadas, por entendermos que qualquer tipo de classificação fixaria verdades, apagaria as ambiguidades contidas nas histórias e reduziria muito o espectro de ressignificação das experiências vividas" (ROSA, RAMOS, 215, p.154). É assim que o diálogo que segue e busca discutir os elementos/sentidos atribuídos contidas nas narrativas, que as "brechas" nos permitem enxergar neste dado momento, ou melhor, os discursos relacionados com a formação continuada, organizadas em dois flancos/sentidos principais de discussão que seguem.

\section{A) Reflexão e práticas pedagógicas: um enlace necessário à formação do professor formador}

Um dos aspectos depreendidos das histórias é o conjunto de conexões entre as narrativas e o processo de reflexão sobre as práticas docentes possibilitado na participação junto aos Ciclos Formativos, em que tais aspectos entrelaçam-se na perspectiva de melhoria das práticas pedagógicas (mônadas 1, 2, 3 e 5).

Para Maldaner (1998, p. 56), o entendimento da sala de aula: "na prática constitui o objeto de pesquisa do Professor e sobre o qual se dá o seu auto aperfeiçoamento profissional”, assim como pôde ser percebido por PESBBio (2019): "eu sempre fui crítico nas minhas aulas, e isso me ajuda a evoluir em termos de Professor. E os Ciclos ajuda eu a pensar mais nessa criticidade do meu ser Professor”. $\quad$ Nesse ponto, PESBBio salienta o exercício de análise de suas aulas como meio de evolução acerca de seus princípios docentes. Consideramos tal perspectiva como fundamental ao processo de constituição docente, quando os Professores, em questão de suas atuações, podem produzir novas compreensões ao processo de ensino, colocamse como sendo sujeitos da transformação. A fim de que o processo torne-se mediador do desenvolvimento docente, Imbernón (2010, p. 23) destaca a participação dos Professores no processo de formação continuada e considera: "fundamental que, no momento de planejar a formação, executá-la e avaliar seus resultados, os Professores participem de todo o processo e que suas opiniões sejam consideradas".

Vários autores têm proposto a importância da reflexão de práticas pedagógicas como contribuinte da melhoria das mesmas (CARR; KEMMIS, 1998; SCHÖN, 1992; ALARCÃO, 2010; GÜLLICH, 2013). Nesse sentido, a importância de tais colocações voltarem-se para 
programas de formação continuada, nos quais, além da investigação individual, é possível a troca entre pares e também a mediação teórica e, por assim ser, tornam-se experiências docentes (LARROSA, 2002). Cambiante ao processo de reflexão, é possível indiciar aspectos relacionados ao compartilhamento de saberes docentes (mônadas 2, 3 e 4), como destacado em: "eu acho importante a gente estar sempre refletindo sobre situações diferentes [...] perceber outras possibilidades de trabalho, outras formas de trabalho" (PESEFis, 2019). Aqui, evocase o sentido da formação compartilhada e da aprendizagem docente como saber experiencial (ZANON, 2003) e, ao mesmo tempo em que o discurso faz um convite ao entendimento de que os Professores participantes se constituem num coletivo no compartilhamento de saberes (LEITE, 2017).

Silva e Schnetzler (2000), ao trabalharem com a formação continuada de Professores, destacam as possibilidades que emanam do espelhamento de práticas, pelas quais:

os Professores participantes ao desenvolverem a leitura, análise e discussão de situações pedagógicas semelhantes às suas puderam se dar conta de suas próprias ações e concepções. Em outras palavras, refletiram sobre suas práticas pedagógicas e sobre as inadequações nelas existentes, percebendo o que priorizavam e o que descartavam em suas salas de aula.

Mediante tais concepções, Silva e Schnetzler (2000) destacam três aspectos a serem considerados em programas de formação continuada, entre eles a necessidade de reflexões sobre a própria prática pedagógica; a superação do distanciamento entre contribuições da pesquisa educacional e a sala de aula; e, ainda, o Professor compreender que sua atividade vai muito além de conhecer o conteúdo e utilizar algumas técnicas pedagógicas, mas como uma categoria empenhada na função social de ensinar. Cabe também apontar que alguns autores da área de Educação em Ciências vêm discutindo processos de formação que estabeleçam aproximações entre a educação básica e Universidade (NÓVOA, 2000; CARVALHO, GIL-PÉREZ, 2000; MALDANER, 2006).

Tais perspectivas também foram enfatizadas pelos Professores formadores (mônadas 2 e 3), como destacado: “Eu não posso perder isso [referindo-se ao diálogo com a educação básica e licenciandos], nem em pensamento e nem em reflexão, nem naquilo que eu posso aproveitar do que os outros estão falando. Então minha preocupação é essa, é tentar sempre trazer a realidade e já estar pensando, se colocando naquele ambiente e não de uma forma distorcida” (PESBQui, 2019). Tal entendimento incita a ideia de que o processo formativo, 
além da reflexão acerca da própria prática e mediado teoricamente, é mais produtivo quanto imbuído de processos interativos, no que pese que a ideia de tríade de interação de Zanon (2003), que é utilizada nos Ciclos.

O modelo de formação destacado pelos Ciclos Formativos está disposto de forma a acolher a formação inicial, Professores da Educação Básica e Professores formadores: tríade de interação (ZANON, 2003) em que todos aprendem e todos ensinam e, por isso, são considerados como Professores em Formação (GÜLLICH, 2017). Dessa forma, “quando eles têm as suas falas a gente consegue se aproximar das angústias que se tem nas escolas e isso é importante que a gente tem que manter, ajudar como formado" (PESBQui, 2019). É viável enfatizar que o processo de formação investigado tem disposto um processo de desenvolvimento docente amplo, ao qual várias interações puderam aqui ser depreendidas e, como "pérolas", são carregadas de sentimentos e significados, por isso encontram-se por entre elementos principais a serem consideradas.

Outro elemento evidente nas narrativas pelo sentido atribuído está relacionado à prática de atuação profissional carregada de experiências que, por via dos encontros de formação, constituem o Professor e daí a necessidade de processos de formação continuada como perspectiva de desconstrução e reconstrução de experiências, apostando na diversidade de olhares que, em movimentos, tornam-se formativos e constitutivos (CUNHA, 2005).

\section{B) Experiências e saberes docentes como contributos da constituição-formação do professor formador}

De que modo os Professores do ES se identificam profissionalmente? Ou como os Professores compreendem suas concepções docentes? São questões que podem nortear uma interpretação para com outros elementos apresentados nas narrativas, que as "brechas" nos permitiram olhar/pensar e tentar compreender.

Em meio aos olhares atentos, observamos fortes interações entre as narrativas quando intencionam aspectos relacionados com a experiência docente (mônadas 1, 2 e 4). Temos considerado, em outros estudos, a noção de experiência como uma concepção de docência, uma vez que o Professor constrói saberes a partir da experiência (TARDIF, 2002; CUNHA, 2005; RADETZKE; GÜLLICH, 2019). Para Cunha (2005), o desenvolvimento profissional docente está alicerçado, também, nos conhecimentos que os Professores produzem ao longo de suas 
atuações, tendo em vista que se referem aos "saberes oriundos da história de vida dos Professores, da formação profissional [...] da prática que realizam como Professores, incorporando o trabalho como espaço e território de aprendizagem" (CUNHA, 2005, p. 57). Esse ponto de vista implica considerar os saberes oriundos da história de vida dos Professores, da formação profissional e de sua prática (CUNHA, 2005), como modelos de constituição docente. Justifica-se por isso a necessidade de discutir tais aspectos com vistas à reflexão formativa.

Cabe em processos de formação continuada colocar em discussão as concepções docentes construídas ao longo da atuação profissional, em que de modo coletivo e compartilhado podem ser configurados como espaços e tempos para construirmos um caminho do meio em termos formativos (SILVA, SCHNETZLER, 2001). No encontro com as narrativas é possível perceber formas de compreensão acerca das experiências docentes. Para PESBBio (2019): “não sei se vou conseguir isso ainda um dia, com quase 50 anos já vem com uma bagagem de quase 20 anos no ensino de graduação, mas aquele ensino tradicional. Mas eu vou quebrando isso a cada ano e os Ciclos pode dar um salto maior a isso”. O Professor Formador, nesse aspecto, ressalta a concepção de que sua atuação docente foi voltada para um ensino tradicional por mais de 20 anos, e assim constituiu-se Professor nessa perspectiva, mas que, a partir dos encontros junto aos Ciclos Formativos, tem investido em uma mudança e esta ideia de transformação lhe é possibilitada pelo processo (CARR; KEMMIS, 1998), bem como pela possibilidade de novas narrativas construídas no coletivo de formação que os Ciclos se tornam.

Tardif (2002) considera que os Professores devem ser considerados como um espaço prático de produção, de transformação e de mobilização de saberes, uma vez que compreende que tanto os Professores da Universidade como os Professores da Educação Básica são portadores e produtores de saberes, de teorias e de ações. Portanto, a [...] relação entre a pesquisa universitária e o trabalho docente nunca é uma relação entre uma teoria e uma prática, mas uma relação entre atores, entre sujeitos cujas práticas são portadoras de saberes (TARDIF, 2002, p. 237). Dessa forma, os saberes docentes são entendidos com plurais e provenientes tanto das instituições de formação profissional, dos currículos como da prática cotidiana (TARDIF, 2002).

Entre os saberes implicados na atividade docente, Tardif (2002) destaca: os saberes da formação profissional; os saberes disciplinares; os saberes curriculares e, por fim, os saberes 
experienciais. Dentre estes, os saberes experienciais assumem posição de destaque, justificandose principalmente pela relação de exterioridade que os Professores mantêm com os demais saberes, pois não controlam sua produção e sua circulação (TARDIF, 2002). Acreditamos que a forma como os Professores direcionam suas práticas pedagógicas está fortemente alicerçada nos esquemas produzidos no decorrer de trajetórias docentes. Tal fato implica considerar movimentos de reflexão com viés de intervenção, compreensão e construção de novos olhares para com o processo de ensinar e aprender.

Essa questão fortalece a ideia de que o diálogo deve partir de situações práticas, como enfatizado por PESEQui (2019): "buscar as experiências da sala de aula, fazer com que os Professores falem da sala de aula, tem vezes que a gente precisa reforçar textos teóricos para ir compreender coisas que ocorrem na sala de aula e na prática”. Tal diálogo fortalece a perspectiva de que a discussão em processos de formação continuada é também teórica, mas sobretudo prática (CARR, KEMMIS, 1998). Para Larrosa (2002), a experiência é uma viagem de ida e de volta. De ida porque instiga a saída para o encontro com o que se passa e de volta, pelas consequências que a aproximação afeta em mim. Noutras palavras, com base em Alarcão (2010), é uma reflexão sobre a prática (retrospectiva) e para a prática (prospectiva), pois a passo que investigamos nossa ação colocada em perspectiva no processo de formação, também a projetamos de modo a transformá-la, disso decorrem as principais intervenções no processo formativo-constitutivo dos professores em formação (GÜLLICH, 2013).

Dessa forma, pela reflexão e nas interações com os outros, constituímo-nos sujeitos capazes de compreender-nos profissionalmente nossas perspectivas: concepções/paradigmas/práticas como Professores, ideia que também é contemplada pelos formadores. Ou seja, "eu acho que é um momento importante porque a gente como formador, tu é formador [perceba], mas tu não está formado, tu está num processo, como eu te disse de constituição, a gente está todo dia aprendendo uma coisa ou outra” (PESEBio, 2019). O processo de (re)constituição docente é, desse modo, necessário aos Professores formadores, uma vez que: "a questão da docência na universidade ultrapassa os processos de sala de aula, pondo em discussão as finalidades do ensino de graduação" (PIMENTA, ANASTASIOU, 2014, p.37). Este processo também precisa estar imbrincado com o contexto político e social. Dessa forma, o processo de constituição docente se reconstrói por intermédio do significado da profissão, da 
revisão das tradições, da questão do conhecimento como Ciência e da construção de saberes pedagógicos (PIMENTA, 1999).

Até aqui, pelas "brechas"/fendas (ROSA, RAMOS, 2015) que olhamos para as narrativas dos Professores, podemos enxergar aproximações e interações que se fortalecem nas leituras e observações focalizadas. Do processo de participação dos Professores junto aos Ciclos Formativos emergem também algumas tensões/conflitos, sobre os quais os Professores, de maneira consciente ou não, revelam em suas narrativas, tais como a dificuldade no processo de escrita reflexiva, o desejo de mais Professores da área básica participarem e mais tempo para discussão. Tais expressões são compreendidas por mim como desafios/ projeções a serem trabalhadas e por isso as pérolas consideradas a cada novo olhar poderão ser outras, ter formas diferentes, uma vez que os ciclos poderão ser outros, estas projeções poderão já ter sido alcançadas e outras/novas poderão surgir.

\section{Formação continuada e constituição docente no Ensino Superior: à guisa de uma conclusão}

É possível pensarmos em formação continuada no ES? Os docentes do ES se constituem Professores em processos de formação continuada? Tais questionamentos reportam-se aos aspectos que procuramos discorrer ao longo do texto, incorporando as potencialidades da formação continuada no desenvolvimento profissional docente. $\mathrm{O}$ diálogo construído junto às narrativas dos Professores formadores fortalece os pressupostos de uma aproximação entre as pesquisas educacionais e a prática docente, quando é a partir das concepções dos Professores que produzimos o estudo.

Acreditamos que, em se tratando de Professores da área básica e da área do ensino, os quais foram analisados aos pares, ${ }^{7}$ não indiciamos diferenças quanto à participação no programa, uma vez que compartilham de situações para as quais acreditam estar participando do processo formativo, entre elas: a reflexão; a discussão de práticas pedagógicas no coletivo de formação; aproximação entre colegas do ES, da Educação Básica e com licenciandos; e ainda o processo de constituição-formação do Professor formador.

\footnotetext{
${ }^{7}$ Os formadores foram consultados aos pares, ou seja, dois Professores da área de Biologia, no entanto um com formação na área básica e outro na área do ensino, e assim para a Física e Química. Tal critério implica um dos objetivos do estudo: compreender se decorrem diferenças quanto à formação continuada junto a cada campo de atuação.
} 
O modelo de formação de Professores, compartilhado com base na IFA crítica, produz um contexto de investigação, formação e ação, ao qual formadores e demais Professores participantes são instigados por processos compartilhados de reflexão a intervirem em suas concepções de ensino, buscando compreendê-las no devir do seu melhoramento. Assim, o contexto projetado pelos Ciclos Formativos potencializa a formação de Professores como sujeitos produtores do próprio desenvolvimento profissional, pondo saberes, concepções e práticas em discussão.

Dessa forma, podemos perceber no desencadear das narrativas docentes apresentadas que os Professores de ES da área de CNT dialogam sobre seus entendimentos, concepções, práticas de formação, bem como que se percebem como sujeitos de uma InvestigAçãoFormAção-Ação e que, em meio a histórias narradas/compartilhadas, buscaram justificar suas ações, compreender suas singularidades e ao mesmo tempo investigaram suas ações, o que os torna/constitui Professores Formadores.

Ao passo que iam pautando dilemas, puderam complexificar a docência no ES e as necessidades desta FormAção, foram sendo também instigados ao discurso acerca do próprio processo de FormAção vivenciado e acerca da responsabilidade de formar/formar-se Professores de Ciências. E, assim, o cenário aos poucos foi ganhando forma e faz surgir:

\section{Das brechas das mônadas: uma nova história coletiva}

Da ideia de que eu não tenho esse habito de escrever, surge a dificuldade que tenho nessa escrita, nessa autorreflexão. Porém ao ver um auditório lotado desse jeito, é uma emoção muito grande e desta forma o compartilhamento que a gente tem lá dentro, das questões teóricas, das experiências vividas, é uma riqueza assim: muito grande. Tem sido proveitoso interagir com licenciandos e Professores da Educação Básica: ouvir os anseios que eles trazem de suas vivências, da escola, sabes? Porque para mim além da formação, é um momento de a gente se reencontrar no grupo. O fato de nós estarmos lá todos juntos sabes? Você pode olhar o grupo todo e olhar quem faz, quem está ali! Isso tudo para nós é muito importante: esse coletivo. É possível observar também a nossa prática enquanto formadores, pois estamos formando Professores uma profissão que precisa ser capaz de transpor conhecimentos conceitos. Provocar esse processo diferenciado de dar aulas é algo que precisa ser construído e os Ciclos 
provoca isso. Então essa é a formação sempre continuada, porque tu estas sempre aprendendo. Tu é formador mas não estás formado, está num processo, como eu te disse de constituição, a gente está todo dia aprendendo uma coisa ou outra. Ass: (PESBBio, 2019), (PESEBio,2019) (PESEQui, 2019), (PESBQui, 2019), (PESBFís, 2019), (PESEFís).

\section{Referências}

ALARCÃO, I. (2005). Formação reflexiva de Professores: estratégias de supervisão. Porto: Porto Editora.

CARR, W., \& KEMMIS, S. (1998). Teoria crítica de la enseñanza: investigación-acción en la formación del Professorado. Barcelona: Martinez Roca.

CUNHA, M. I. da. (1998). O professor universitário na transição de paradigmas. Araraquara: JM Editora.

CUNHA, M. I. da. (2005). Formatos avaliativos e concepção de docência. Campinas: Autores Associados.

GAUTHIER, C. (2006). Por uma teoria da pedagogia: pesquisas contemporâneas sobre ofazer docente. Ijuí: Ed. Unijuí.

GÜLLICH, R. I. da C. (2013). Investigação-Formação-Ação em Ciências: um caminho para reconstruir a relação entre Livro Didático, o Professor e o Ensino. Curitiba: Prismas.

IMBERNÓN, F. (2001). Formação docente e Profissional: Formar-se para a mudança e a incerteza. São Paulo: Cortez.

JUNGES, K. dos S. J., \& BEHRENS, M. A. (2015). Prática docente no Ensino Superior: a formação pedagógica como mobilizadora de mudança. PERSPECTIVA, 33(1), 285-317.

LARROSA, J. (2002). Notas sobre a experiência e o saber de experiência. Revista Brasileira de Educação, 1(19), 20-28.

LÜDKE, M., \& ANDRÉ, M. (1986). Pesquisa em educação: abordagens qualitativas. São Paulo: E.P.U.

MALDANER, O. A. (1997). A formação inicial e continuada de Professores de Química: Professores/pesquisadores. Tese de doutorado, Unicamp, Faculdade de Educação, Campinas.

MALDANER, O. A. (2006). A formação inicial e continuada de Professores de Química: Professores/pesquisadores. Ijuí: UNIJUÍ.

MIZUKAMI, M. da G. N. (2002). Escola e aprendizagem da docência: processos de investigação e formação. São Carlo: EDUFSCar.

NÓVOA, A. (2007). Vidas de Professores. Porto: Porto Editora.

NÓVOA, A. (2009). Professores: Imagens do futuro presente. Lisboa: Educa.

PERSON, V. A., \& GÜLLICH, R. da C. (2016). Demarcando elementos constitutivos da formação continuada de Professores de ciências. In BONOTTO, D. de L., LEITE, F. de 
A., \& GÜLLICH, R. I. da C.. Movimentos formativos: desafios para pensar a educação em ciências e matemática. Tubarão: Copiart.

PIMENTA, S. G. (1999). Formação de professores: saberes e identidades. In PIMENTA, S. G. (Org.). Saberes pedagógicos e atividade docente. São Paulo: Cortez.

PIMENTA, S. G., \& ANASTASIOU, L. das G. C. (2014). Docência no ensino superior. São Paulo: Cortez.

PORLÁN, R., MARTÍN, J. (1997). El diario del profesor. Sevilla: Díada Editora.

RADETZKE, F. S., \& GÜLLICH, R. I. da C. (2019). As pesquisas sobre a docência no ensino superior em contexto brasileiro: desafios para pensar a formação em ciências. Rev. Inter. Educ. Sup. 6(1), 1-25.

REIS, G. A. de S. V. (2016). Formação continuada e prática pedagógica: percursos e narrativas de Professores da educação infantil. Dissertação de mestrado - Faculdade de Educação da Universidade Federal Fluminense, Niterói.

REIS, G. A. de S. V. (2018). (2018). Compartilhar, estudar, ampliar olhares: narrativas docentes sobre formação continuada. Educação e Pesquisa 44(1), 1-18.

REIS, P. (2008). As narrativas na formação de Professores e na investigação em educação. Nuances 15(16), 17-34.

ROSA, M. I. P., \& RAMOS, T. A. (2015). Identidades docentes no Ensino Médio: investigando narrativas a partir de práticas curriculares disciplinares. Pro-Posições 26 (1), 141-160.

SCHÖN, D. (1992). Formar Professores como profissionais reflexivos. In: NÓVOA, A. Os Professores e a sua formação. Lisboa, Dom Quixote.

SILVA, L. H. de A. (2016). Formação de Professores de ciências: problemáticas, paradigmas e desafios para mudança. In BONOTTO, D. de L; LEITE, F. de A., \& GÜLLICH, R. I. da C. Movimentos formativos: desafios para pensar a educação em ciências e matemática. Tubarão: Copiart.

SILVA, L. H. de A., \& SCHNETZLER, R. P. (2000). Buscando o caminho do meio: a "sala de espelhos" na construção de parcerias entre professores e formadores de professores de Ciências. Ciência e Educação 6 (1), 43-54.

TARDIF, M. (2002). Saberes docentes e formação profissional. Petrópolis: Vozes.

ZANON, L. B. (2003). Interações de licenciandos, formadores e Professores na elaboração conceitual de prática docente: módulos triádicos na licenciatura de Química. Tese de doutorado. Universidade Metodista de Piracicaba-UNIMEP, Faculdade de Ciências Humanas, Piracicaba.

Autores:

Franciele Siqueira Radetzke. francielesradetzke@gmail.com. https://orcid.org/0000-0002-3222-7977 Universidade Federal da Fronteira Sul (UFFS), Brasil 
Bacharel em Química e Mestranda do Programa de Pós-Graduação em Ensino de Ciências PPGEC / CAPES da Universidade Federal da Fronteira Sul (UFFS). Temas de Pesquisa: Formação Contínua de Professores, Práticas Pedagógicas, Constituição de Ensino, Ensino de Ciências e Química.

Roque Ismael da Costa Güllich

bioroque.girua@gmail.com https://orcid.org/0000-0002-8597-4909

Universidade Federal da Fronteira Sul (UFFS), Brasil Doutor em Educação nas Ciências. Professor e Coordenador do Programa de Pós-Graduação em Ensino de Ciências - PPGEC/CAPES na Universidade Federal da Fronteira Sul (UFFS). Temas Investigados: Ensino de Ciências e Biologia, Formação de Professores, InvestigaçãoFormação-Ação, Pensamento Crítico. 